\title{
MEANING, UNDERSTANDING, AND KNOWING-WHAT: AN INDIAN GRAMMARIAN NOTION OF INTUITION (PRATIBHĀ)
}

\section{Chien-hsing Ho}

Graduate Institute of Religious Studies, Nanhua University

chho@mail.nhu.edu.tw

\section{Prologue}

For Bhartṛhari, a fifth-century philosopher of the Indian Grammarian (Vaiyākaraṇika) school, all conscious beings-beasts, birds and humans-are capable of what he called pratibhā, a flash of indescribable intuitive understanding such that one knows what the present object "means" and what to do with it. Contemporary scholars writing on pratibhā generally translate the Sanskrit term as "intuition," not in the sense understood by many analytical philosophers as an a priori judgment appealed to in thought experiments to test philosophical hypotheses, but in the sense of a spontaneously arising awareness that is immediate, reliable, indescribable, and pregnant with meaning. Significantly, our instantaneous understanding of a sentence or complete utterance already counts as an instance of pratibhā. Given that to understand a sentence is to know its meaning, such an understanding, if correct, amounts to a mode of knowing that may best be termed knowing-what, to distinguish it from both knowing-that and knowing-how.

This essay attempts to expound Bhartrhhari's conception of pratibhā in relation to the notions of meaning, understanding, and knowing laid out in his magnum opus, the Vākyapadīya (henceforth VP). ${ }^{1}$ The conception is philosophically intriguing and contemporarily relevant. Yet, it has not hitherto been subjected to a systematic analytical philosophical treatment. ${ }^{2}$ Here, I hope to fill this lacuna.

Now, to offer a broadly coherent and focused philosophical analysis, I shall neglect the metaphysical and presumably exotic aspects of the conception. My overall purpose is to provide a rational reconstruction of Bhartrhhari's empirical thought on pratibhā to suggest its relevance for contemporary studies of related topics.

I identify three different yet interrelated notions of pratibhā: intuitive meaning, intuitive understanding, and knowing-what. The remainder of the essay deals with each in turn. In "Intuitive Meaning," I touch briefly on Bhartrhhari's views of consciousness and language, and examine at some length his indescribability thesis concerning the intuitive meaning of a sentence. In "Intuitive Understanding," I delineate the general features of pratibhā as intuitive understanding and discuss its probable range in relation to expert intuition and sense perception. Thereafter, in "Knowingwhat," I relate pratibhā to the notion of knowing-what and show why these two notions are to be differentiated from knowing-that and knowing-how. I conclude 
with some remarks on the contemporary relevance of Bhartrhari's conception of pratibhā.

\section{Intuitive Meaning}

Bhartrhari's philosophy affirms the omnipresent and world-constituting character of language while revealing holistic and monistic tones. He is well known for claiming that all awareness appears as if permeated by words. It is by dint of words that consciousness is capable of illuminating its object, that one is able to grasp distinctions among things. Meanwhile, Bhartrhari has a holistic preference for that which is conceptually undifferentiated; for him, a whole is typically more real than its parts. He goes on, it seems, to posit an undivided and linguistic reality as the ultimate source of myriad things in the world. ${ }^{3}$ However, I shall not discuss such metaphysical or quasi-metaphysical aspects of his philosophy, but will confine my discussion to the generally empirical dimension.

Equally unmistakable is the fact that for Bhartrhari the nature and functioning of language is closely interlinked with that of consciousness. A perceptual awareness or an episode of perceptual consciousness consists of the act of perception and the immanently known form of its external object. Let us call such a form a percept. For example, when I see a gray treepie bird, there would appear in my consciousness a gray-treepie percept, which results from it having being illuminated and assimilated by the consciousness. ${ }^{4}$ In Bhartrhari's view, further, consciousness is self-aware in that both the act and the percept are instantaneously and immanently known to consciousness itself. In perception, one is aware of both the perceptual act and the intentional percept. ${ }^{5}$ Similarly, in understanding a word, one is aware of both the signifying word and its signified meaning. ${ }^{6}$ Here, Bhartrhhari takes the meaning (artha) of a word like "treepie" to be an immanent intentional object (buddhivișaya)—basically the form or image appearing in the awareness of understanding the word - which has as its ground an external object and is externally imposed. ${ }^{7}$ For him, the understanding can occur even if no concerned external object is present.

For Bhartrhari, the primary meaningful unit of language is the sentence, not the word. Only a sentence or complete utterance conveys a clear and complete meaning and prompts the hearer to action. Words, by contrast, express their meanings only in the context of a sentence. In fact, Bhartrhari would tend to view the meanings of words in isolation as imaginary constructs. Consequently, he normally uses the term pratibhā to represent the instantaneous understanding of a sentence and the correlative sentence meaning, but not word understanding and word meaning. Significantly, the sentence meaning is also mental, or, we may say, intentionally immanent in character. ${ }^{8}$ Additionally, the percept and the sentence meaning are alike in that they both figure as gestalt-like wholes that cannot be reduced to a mere aggregation of their constituents. Let us now focus on the notion of sentence meaning as an instance of pratibhā.

With Bhartrhari's emphasis on linguistic practice and consciousness, the notion of sentence meaning discussed here is not the conventional or semantic meaning of 
a sentence, but what the hearer intentionally apprehends at the precise moment she understands a complete utterance. In the process of comprehending a sentence, we typically apprehend its constituent words and their indefinite meanings individually and sequentially. Toward the end of the process, according to Bhartrhari, a distinct sentence meaning as pratibhā may appear in a flash, brought forth by the word meanings. Let us term such a meaning intuitive meaning, using the adjective "intuitive" to capture the immediate, holistic, and somehow indescribable character of the meaning. Here is how Bhartṛhari characterizes it in the $V P:{ }^{9}$

It [i.e., the intuitive meaning] cannot be explained to others as "it is this." Though its existence is borne out by one's own experiential activity, even the agent herself cannot render a description of it. (2.144) While being beyond analytical reflection, it seems to complete the combination of the word meanings and assume, as it were, the whole form [covering all the meanings]. It figures as an object. (2.145)

Upon hearing a sentence that is understood, an intuitive meaning spontaneously occurs as the intentional correlate of the act of sentence understanding and is immanently and distinctively known or experienced by the hearer. This fact shows itself in the hearer's knowing what to do in response to the sentence.

For Bhartrhari, one can directly and instantly experience the intuitive meaning of a sentence, which, we may say, approximates what it is like to understand what the sentence means. ${ }^{10}$ While probably many would concede that upon understanding a sentence a somewhat unitary meaning or sense appears and is experienced in consciousness, what is remarkable here is Bhartṛhari's view that the intuitive meaning cannot be properly verbalized. He sees a limit of language right in linguistic understanding! We may ascribe to him the following Indescribability Thesis: that the intuitive meaning that is directly experienced in linguistic understanding cannot be adequately expressed as it truly is by words. Significantly, the indescribability does not arise because the meaning is unique and private to every individual. The meaning is as ineffable to oneself as it is incommunicable to others. Bhartrhari does not posit any kind of private language to address the problem.

If someone does not know what it is like to see lavender, we can hardly describe to him what seeing the color is like. We may just show it by inducing in him a visual experience of the color. Similarly, if one is ignorant of what it is like to understand what is meant by the sentence "Lavender is extensively used in aromatherapy," we may make sure he understands the meaning of the words concerned and then induce in him the relevant experience of sentence understanding. It is not easy to put adequately into words the experienced (intuitive) meaning. ${ }^{11}$ Bhartrhari could be hinting at this when, in VP2.421-422, he explains the difference between the particularized experience of sentence meaning and the indefinite apprehension of word meaning by referring to that between the actual experience of being burnt and the mere apprehension of the meaning of the word "burn." In any case, I detect in the VP three interrelated reasons for the indescribability thesis, to which we shall now attend.

To state the first reason: for Bhartrhari, intuitive meaning is of the nature of interrelation between word meanings, while a relation in itself cannot be described. A 
relation is not determinately cognizable; it lacks an independent form on which words can alight, because it depends entirely on the items that are related by it. ${ }^{12}$ In addition, given the entity-like nature of nouns, any noun used to signify the relation inevitably turns it into an entity that possesses a relation, but not the relation as such. ${ }^{13}$ We then reformulate the reason as the following argument:

A1. The intuitive meaning of a sentence is of the nature of a relation, because it knits together the meanings of the words that constitute the sentence.

A2. A relation is indescribable, for it is indeterminate and cannot be expressed without being turned into a relatum.

A3. Hence, the intuitive meaning is indescribable in words.

In an essay that touches upon the issue of ineffability, it is advisable here to explain the sense in which words can be said to directly and properly express, that is, to describe, their objects. Broadly following Bhartrhari, we may take the semantic object of a word, that is, that which is directly and properly expressed by a word, to be what the word is invariably and referentially connected to in each of its literal uses in a sentence and when it is used with the same meaning. The semantic correlate of words that form a sentence can be understood mutatis mutandis. Now, words that form a sentence directly and properly express a thing if and only if their semantic correlate conforms to the thing. If the correlate does not conform to the thing, then the words fail to describe it. A Christian theologian, for example, may consider God ineffable on the ground that the subject-predicate form of the language that we use connotes a semantic correlate that represents a division between a substance and its attributes, yet God is altogether one and simple in Himself. The semantic correlate of language is structured, with distinctions due to word meanings, yet the Deity is taken to be void of division and structure.

Language operates in the realms of generality or semblance, and the sentential form of language, together with the distinctions due to word meanings, indicates that the semantic correlate of a sentence is structured and does not conform to things that are devoid of division and structure. Thus, Bhartrhari is of the view that an item that is devoid of division and structure, and so lacks a distinct basis for the application of words, is indescribable in itself. ${ }^{14}$ With regard to our case, the sentence "The sky is clear" may express a semantic correlate composed of distinct relata, whereas the intuitive meaning known from the sentence is an interrelation of the form, say, of "the-sky-is-clear." The correlate does not conform to the meaning. Hence, the indescribability thesis follows. ${ }^{15}$

One may, of course, have doubts about premise A1. However, Bhartrhari also contends that an intuitive meaning is divisionless and sequenceless, which may count as the second reason for the thesis. Even though the meaning results from the combination of word meanings, it is actually a unitary, structureless whole that is beyond analytical reflection. ${ }^{16}$ It cannot be put into words, for the mere combination of word meanings entails a structure that fails to conform to it. Here is the argument: 
B1. The intuitive meaning of a sentence is a unitary, structureless whole that cannot be analyzed and reduced to the mere combination of word meanings.

B2. Any sentence used to express the meaning invariably connotes a semantic structure that fails to conform to it.

B3. Hence, the intuitive meaning is indescribable in words.

Again, one may question the tenability of premise B1. How can a sentence meaning that arises out of distinct word meanings be without division? Let us then consider the third reason for holding the indescribability thesis, which concerns the irreducibility of an effect to its causes. For Bhartrinari, an effect arises spontaneously and distinctly from a set of causal factors and is not related to them in a definite manner. The effect as a unitary, previously non-existent item is said to come into existence by a wonderful process-one may think of the intoxicating power of wine in relation to its causal materials. As a result, its nature cannot be described and properly revealed by reference to its causal factors.

In understanding a sentence, we sequentially apprehend its constituent words and their meanings, and the meanings may leave in our subliminal consciousness their residual traces, which finally help to bring forth the intuitive meaning. The meaning, which figures as an undifferentiated gestalt, even though it depends causally on the vaguely known word meanings, is far more than their mere conglomeration. It results from the interrelating of the word meanings in such a way that it does not reside in any of the meanings taken singly or collectively, and cannot be described by reference to them. ${ }^{17}$ Given the foregoing, we may formulate the following argument:

C1. An effect that arises from a set of causal factors is irreducible to a mere conglomeration of the factors and cannot be described by reference to them.

$\mathrm{C} 2$. The intuitive meaning of a sentence is an effect that arises from the meanings of its constituent words.

$\mathrm{C} 3$. Hence, the intuitive meaning cannot be described in reference to the word meanings.

In daily linguistic practice, we may analyze a sentence meaning based on the word meanings. Yet, this is only an expedient measure for better understanding the sentence. The intuitive meaning of the sentence "The sky is clear," being a distinct effect, cannot be revealed as it truly is by a mere juxtaposition of the words "the," "sky," "is," and "clear." Appeal to other words surely cannot do any better.

We seem to be facing a paradox: the intuitive meaning that is known by understanding a sentence cannot be described by the sentence itself. However, this only indicates that the experientially known meaning of a sentence differs distinctly from the abstractly considered semantic meaning of the same sentence, the latter being the semantic correlate of the sentence. Put conceptually, but not linguistically, the correlate would be replaced by a propositional, structured thought that consists of 
compositionally combined concepts. Still, such a thought is no match for the intuitive meaning.

Nevertheless, Bhartrhari must have overemphasized the distinct, undifferentiated character of the intuitive meaning. VP 2.145, quoted above, implies that the intuitive meaning seemingly comprises within itself all the word meanings. Indeed, the word meanings as cooperating factors for the intuitive meaning occur both before and simultaneously with the meaning. After the sequentially and indefinitely apprehended word meanings give rise to the intuitive meaning, the latter, while making the meanings less indefinite, is intertwined with, and somewhat differentiated by them. If so, the meaning is not as divisionless as Bhartrhari would like to take it to be, and may instead be endowed with a texture of interrelated word meanings such that the indescribability thesis should only be taken with a pinch of salt. Still, this observation does not necessarily invalidate the thesis, which should remain worthy of our consideration.

It is worthwhile at this point to turn to Michael Polanyi's theory of tacit knowing for further elucidation. For Polanyi, every object-directed awareness has a tacit, inarticulate root. In wielding a hammer to drive a nail, for example, one watches the effects of the strokes on the nail and is also aware of the feelings in the hand that is holding the hammer, which guide one's handling of it effectively. Yet the feelings are not attended to in the way that one attends to the effects. Here, one knows the feelings only by relying on them for attending to the hammer hitting the nail, and so one has only what Polanyi calls subsidiary awareness of the feelings, which, we may say, is merged into one's focal awareness of driving the nail. ${ }^{18}$ Likewise, in many other conscious activities, one focally attends to a coherent item that emerges from one's integrating various assisting factors, which are called subsidiaries, of which, as a result of such integration, one becomes only tacitly and subsidiarily aware. Often, one first needs to attend to the subsidiaries focally. If one is skillful or knowledgeable enough to perform the integration, one then integrates the subsidiaries to attend to the emerging focus, which, interestingly, is said to be their meaning or joint significance. Meanwhile, if one turns one's attention back to (some of) the subsidiaries, the latter become the foci while being deprived of their meaning just as the previous focus is relinquished.

Polanyi applies his theory to various fields, including linguistic practice. "The most pregnant carriers of meaning," says he, "are of course the words of a language." ${ }^{\prime 19}$ We may say that when one hears a series of audible words that constitute an utterance, one integrates the words and their meanings in order to attend focally to the meaning of the utterance. At the end of this process, one is only tacitly aware of the word meanings. Similarly, for Bhartrhari, in understanding a word in a sentence, one first attends to its sound and apprehends its true form as a signifier; then the word becomes a remainder, secondary to the now-attended meaning. Likewise, in understanding the sentence, the word meanings, after being known sequentially and vaguely, fuse together with the result that the meaning of the sentence distinctly appears in a flash. Bhartrhari agrees that when the sentence meaning is obscure, one 
may re-attend to some of the constituent words in order to have a re-fusion of the word meanings that results in the appearing of a clear sentence meaning.

By "tacit knowing," Polanyi mainly means the act of knowing involved in one's tacitly integrating the subsidiaries into the coherent focal entity as their joint meaning. One point of his theory of tacit knowing is that the product of a tacit integration cannot be reduced to a mere summation of its detectable subsidiaries. This is also what Bhartrhari is driving at when he speaks of intuitive meaning being beyond analytical reflection. However, while Bhartṛhari stresses the indescribability of the meaning, Polanyi highlights the unspecifiability of the subsidiaries and the ineffability of their tacit knowledge. ${ }^{20}$ Still, given that in many cases the focal entity is formed jointly by the subsidiaries, the latter's unspecifiability and the ineffability of the relation between them make it hard to describe the entity adequately. ${ }^{21}$ In any case, Polanyi's notion of tacit integration and his claim that we know more than we can say may help in elucidating and strengthening Bhartrhari's ideas on intuitive meaning and understanding. We also note his view to the effect that all kinds of rational knowing involve the knower's existential participation and are shaped and sustained by certain inarticulate mental faculties that we share with nonhuman animals.

\section{Intuitive Understanding}

It is no coincidence that, for Bhartṛhari, the term pratibhā stands for sentence understanding as well as sentence meaning. The intuitive meaning qua sentence meaning, being the inner intentional object of an understanding act, is immanent in the awareness of sentence understanding, whereas the awareness, comprising within itself both the act and the meaning, is said to be a unitary, indivisible whole. It is through conceptual analysis that we hold the act and the meaning apart. ${ }^{22}$ Here, a sentence understanding is a spontaneously arising, unitary awareness that comprises both the act and the meaning, and the previously mentioned indescribability of the meaning can readily be extended to that of the understanding.

Significantly, sentence understanding is only a paradigmatic case for Bhartrhari's notion of pratibhā as a flash of indescribable understanding such that one knows what the present object means and what to do with it. Let us use the term "intuitive understanding" or simply "intuition" for this notion. ${ }^{23}$ The notion can be applied across a wide range, although it is difficult to ascertain precisely what that range is. For our purposes, and on the basis of my reading of the passages in the VP that concern the notion, let us first delineate the general features of pratibhā as intuitive understanding: (1) it cannot be adequately described, given mainly the indescribability of its intentional content; ${ }^{24}$ (2) it arises spontaneously in a flash, following a tacit integration that involves the presence of words or linguistic traces (śabdabhāvanā) and depends on repeated practice or nature/instinct, such that it cannot be reduced to a mere summation of its causal factors and constituents; (3) it is an immediate, noninferential awareness of an object for what it "means" as well as of what to do with it, and is generally considered reliable concerning what it reveals; and (4) its 
content cannot be transmitted to others-everyone has to acquire it through their own practices and experiences. The last three features will become clearer as we proceed to discuss the probable range of intuitive understanding.

Why is sentence understanding a paradigm case for pratibhā? Bharțhari, as a grammarian-philosopher, recognizes the centrality of language in all our theoretical and practical activities. In his view, our experiences of daily life are invariably impregnated with words. However, he also has a notion of linguistic traces and of inarticulate words (anākhyeyaśabda). Bhartṛhari was a Hindu who believed in the doctrine of rebirth, and, for him, we have all used language a great number of times in this and previous lives. Such linguistic activities have left in the subliminal consciousness numerous linguistic traces waiting to be awakened. ${ }^{25}$ When certain traces are awakened, they give rise to articulate and inarticulate words on the surface of consciousness. ${ }^{26}$ It is hard to tell what precisely Bhartrhari takes inarticulate words to be. Yet, we know that such words are present in the consciousness of an infant without language; they also occur in an adult's perceptual awareness when the object is not yet attentively and determinately cognized. He can indeed claim that all awareness appears as if permeated by words.

Thus, our comprehension of things in the world can sometimes be broadly similar to sentence understanding. We may understand in a flash a facial expression, a perceived state of affairs, an abrupt situation, or the quality of a jewel, by virtue of experiencing a coherent meaning therein, while knowing what to do with it. The understanding spontaneously arises through our tacitly integrating the experienced aspects of the object as well as the articulate/inarticulate words and their meanings. That would be an intuitive understanding if it bears the aforementioned features.

The following verses in the VP indicate the functioning, significance, and farreaching presence of an intuitive understanding:

Concerning what is to be done, no one can transgress that [intuitive understanding] which arises either directly from words or through the working of linguistic traces. (2.146) The whole world considers it to be a reliable means of knowledge (pramāna). Even the activities of animals proceed by dint of it. (2.147) Just as the power to intoxicate and the like appear spontaneously in certain substances by mere maturity, likewise are intuitive understandings [that emerge in the consciousness] of those who have them. (2.148)

The intuitive understanding that arises directly from words is presumably intuition as sentence understanding, which results from the comprehension of audible words in an utterance, whereas other types of intuitive understanding (whatever they are) occur through the working of linguistic traces, which bring forth inner words that induce the intuition concerned. Either way, the emerging intuitive understanding typically gives one the best guidance regarding what the appropriate action is to take here and now.

Who causes infants to move their speech organs to utter meaningful sounds for the first time? Who teaches pigeons to build nests for breeding? Who drives a rat, trained to run a maze, to succeed in finding its way out even when blindfolded? Neither human infants nor nonhuman animals have an articulate language. Yet given the 
doctrine of rebirth, they are, for Bhartrhari, endowed with linguistic traces that help to induce in their mind an intuitive understanding that guides them in their purposive activities. This might explain why little children who are learning a language may utter completely new sentences in a way that surprises their elders. However, this idea is unpersuasive to those of us who have no belief in rebirth, and Bhartrhari would be left nearly only with nature or instinct to appeal to for explaining animals' spontaneous, appropriate activities. ${ }^{27}$

Meanwhile, Bhartrhari highlights repeated practice as an important factor for the arising of intuitive understanding. Our ability to understand sentences of our native language already hinges on long-term linguistic practice in early childhood and thereafter. Here, Bhartrhari appears to take expert intuition to be a form of intuitive understanding. ${ }^{28}$ In VP 1.35, he refers to an expert's truthful awareness of precious stones, which, he says, is born of practice but not of inference, and cannot be communicated to others. To become a connoisseur of jewelry, for example, one needs to receive instruction and training from jewelry experts, together with years of practice in discerning different types of jewel. A connoisseur's intuition of a jewel for what it is arises from a tacit integration of her verbal knowledge of jewelry, various visual cues, and so forth; the learned concepts in the knowledge become only subsidiaries to what she intuitively knows, and she may have difficulty in describing the latter. Tacit integration, as Polanyi tells us, differs from deductive inference in that inference connects two focal items, the premises and consequents, while integration makes subsidiaries bear on one focus. In addition, the Commentary on VP 1.35 states that the causal or constituent factors (pada, hetu) for an expert's intuition are subtle or fine-grained and cannot be explained to others. ${ }^{29}$ In any case, we can well ascribe to Bhartrhari the view that an intuitive understanding does not arise from any conscious use of reason.

Of course, an expert's intuition generally gives rise to an intuitive judgment about the object in question, and she may manage to say something about the probable reasons for the judgment. Yet, were the intentional content and immediate causal factors of the intuition adequately describable, the content would be transmittable. If the content could be transmitted to others, a novice would have the intuition merely by hearing the expert's words, which is absurd. Plainly, everyone has to acquire intuition through repeated practice.

Both sentence understanding and expert intuition are intellective in character. What of skillful and practical knowing such as knowing how to swim or knead bread? ${ }^{30}$ Should we treat knowing-how as a kind of intuitive understanding? The view that the content of intuitive understanding cannot be transmitted to others reminds us of the story about an old wheelwright in the Chinese Daoist text Zhuangzi. This old man spoke of his know-how for subtly chiseling a wheel, which was acquired in the hand and felt in the mind but could not be put into words. He complained that he could not impart his expertise to his son and so he said, "I've gone along for seventy years and at my age I'm still chiseling wheels." ${ }^{31}$ In the $V P$, Bhartrhari does not discuss pratibhā in relation to skills and skillful knowing, although he does assert that all crafts are based on an awareness that is linguistic in nature, supposedly refer- 
ring to the prolonged process of acquiring craft skills wherein an apprentice tries to comprehend the master's instructions and closely watch and emulate the latter's efforts at getting the work done. Now, a knowing-how typically depends on repeated practice and has an ineffable content that cannot be transmitted. Yet, it does not seem to arise spontaneously in a flash, nor is it an immediate awareness of an object for the intuitive meaning. Given the lack of the second and third features delineated above, it is advisable not to include knowing-how under the notion of intuitive understanding.

Furthermore, can we count sense perception as a form of intuitive understanding? Although Bhartrhari appears to treat as cases of intuitive understanding certain supersensory perceptions (such as those that result from the discipline of yoga), the $V P$ does not clearly place sense perception under the notion of pratibhā. Indeed, if sense experiences are invariably impregnated with words, they might be so conceptual as to exclude any indescribable content. As we have seen, however, by "words" Bhartrhari may include inarticulate words, which we supposedly share with animals. ${ }^{32}$ Besides, even if articulate words or verbalizable concepts are always present in a human adult's sense perception, this might well be a contingent fact rather than what is integral to the perception.

VP 1.53 and 2.7 imply that the percept in sense experience, like sentence meaning, is an indivisible whole. According to a passage in the Commentary on VP 1.26, a thing of interrelated constituents first appears to an awareness as a whole, but may then be deliberately divided in order to focus on different constituents; yet, for the arising of an intuitive understanding that leads to purposeful activity, one needs to unite the constituents and once again comprehend the thing in its closely interrelated form. ${ }^{33}$ It is quite clear that for Bhartrhari an intuitive understanding may occur in sense experience.

Suppose, for example, a person who is afraid of snakes suddenly sees a snake when walking past a bush. The person may at that very moment understand the snake in a flash by virtue of experiencing a coherent but indescribable meaning therein, while knowing to step back immediately. This understanding arises from the person instantly integrating the perceived aspects of the snake, the past experiences of snakes, and other things. This would not be very different from the intuition a hungry raccoon may have on seeing the snake, even though the two intuitions will result in very different actions.

Nevertheless, what is the intuitive meaning that figures in such sense experiences? The meaning is perhaps close to what Michael Dummett has chosen to call "proto-thought." For Dummett, the notion of proto-thought serves to account for the fundamental non-sensory component of sense perception that we share with animals. A dog can distinguish between being attacked by one hostile dog and by several, yet we cannot seriously ascribe to him the thought, "There is only one dog there." The dog has only proto-thoughts, which cannot be accurately expressed in words, because they do not have the structure of verbally expressed thoughts. Whereas proto-thought, unlike full-fledged thought, does not have language as its vehicle and cannot be detached from present situations, it may enable us, on seeing an 
object, immediately to recognize the object according to its type, say, as a dog, a tree, et cetera, and may evoke specific behavioral responses on our part. ${ }^{34}$

The intuitive meaning as the intentional content of intuitive understanding is presumably more holistic and less differentiated than Dummett's proto-thought. While it is difficult to say precisely what it is (after all, it is indescribable!), Bhartrhari may agree that neither does an intuitive sense experience involve a conceptual judgmental content that can be verbalized properly, nor is it a non-conceptual experience that was believed by some Buddhist epistemologists to be alone capable of manifesting the object as it truly is. It seems to me implausible that, upon seeing a snake, concepts like "snake" or propositional thoughts like "that is a snake" would always in the first place figure in one's visual experience. Instead, one may first see the creature meaningfully in the sense of apprehending its meaning of the unitary form, say, "that-is-a-snake!" and act immediately without any reflection in the middle. If the experience involves a conceptual judgment, one would not act instantly; if it were wholly non-conceptual, one would not act at all. In any case, I concur that our sense perception is often loaded with concepts. What is suggested here is only that sense experience can in some cases bear the previously mentioned features and therefore count as a form of intuitive understanding.

Finally, while Bhartrhari notes the occasional unreliability of sense perception, inference, and verbal testimony, which are regarded by many traditional Indian philosophers, perhaps even by himself, as chief means of knowledge, he claims in VP 2.147 that the whole world takes intuitive understanding to be reliable. Such a claim is not groundless. Even if the uttered sentence "The tea is tasty" and my resultant judgment that the tea is tasty are both false, my intuitive understanding of the sentence is correct insofar as I correctly apprehend the meaning of the sentence. The understanding would only be considered incorrect if I misunderstand the sentence. Again, expert intuitions are penetrative and typically trustworthy. Moreover, several contemporary studies indicate that people tend to trust and use their intuitions when they are in positive mood states; also, in many decision-making situations, intuition is considered more effective and accurate than analysis. ${ }^{35}$ That said, Bhartṛhari does not assert that intuitive understanding is infallible, and it seems advisable to take it to be connected with the possibility of being mistaken.

\section{Knowing-what}

In the preceding section, we discussed the general features and probable range of intuitive understanding as pratibhā. Although the understanding is not infallible, it is considered generally correct. When correct, the understanding amounts to a mode of knowing. For some reasons, such a knowing, which I have termed knowing-what, should be distinguished from both knowing-that and knowing-how. The present section is meant to address this issue.

Gilbert Ryle's cerebrated distinction between knowledge-that and knowledgehow, which he presented in his 1949 book The Concept of Mind, has recently been debated among analytical philosophers. Some thinkers dismiss the distinction and 
attempt to show that knowledge-how is indeed a species of knowledge-that, ${ }^{36}$ while others argue against any wholesale reduction of knowledge-how to knowledgethat. ${ }^{37}$ I cannot here explore this issue at length, but merely make a few preliminary points pertinent to my approach.

(1) A semantic analysis of "knowing how" sentences can indeed lend support to the view that knowledge-how is a species of knowledge-that. After all, in many uses of the linguistic form "know how to $\Phi$ " (where $\Phi$ denotes an activity), what is expressed is clearly knowledge-that, as when we say "Jim knows how to go to the park" (he knows that the route is such and such). However, in our concern with types of knowledge, we should rather attend to the substantive message of utterances, not the precise verbal formulations that are used. Ryle was originally concerned with the message. If so, we may construe the term "knowledge-how" prescriptively to mean practical knowledge, roughly a practical ability to do something, which involves embodied, action-centered and normally learned skills that are developed through actual bodily performance. By contrast, the term "knowledge-that" refers to factual, propositional knowledge, roughly a true (dispositional) belief that is describable and has an appropriate warrant. ${ }^{38}$

(2) I suggest we use the term "knowing" in the occurrent sense, and "knowledge" in the dispositional sense. A knowing-that is basically a true, warranted cognition harboring a conceptual thought that can be articulated in the form of a proposition that tells how things stand. It will then become dispositional as a knowledge-that. A knowing-how, meanwhile, is an agent's good or successful manifestation of her practical ability as knowledge-how. Here, a person may be said to know how to $\Phi$, yet be unable to $\Phi$ successfully. Suppose an accident left a master pianist's arms severely paralyzed. For a certain time period she would still have the knowledge-how, the ability, to play the piano, but would have no knowing-how, being now unable to play successfully. In a way, she both knows and knows not how to play the piano. The point is that she would not lose her ability overnight; if, soon after the accident, her paralysis was magically cured, her masterly ability would again be manifested in actual musical performance.

(3) One may have consciously accessible beliefs about one's knowledge-how, yet, as the wheelwright story tells, it is difficult to clearly articulate and impart the knowledge proper. One may know how to ride a bicycle without any conceptual understanding of how one maintains balance. One cannot learn to play bowls just by reading a book on the game; one must practice it to get the knack. There is an ineffable content in one's knowledge-how. In addition, knowing how to swim and knowing that one is swimming are plainly two phenomenologically distinct episodes. Hence, the irreducibility of knowledge-how (and knowing-how).

Now, one may think that the two types of knowing/knowledge depicted above are jointly exhaustive. The duality between them corresponds to that between theory and practice, thinking and doing, and intellect and will. As with many dualities and dichotomies in philosophy, however, to challenge and bridge it can be philosophically rewarding. To begin with, Polanyi has already taken his tacit knowing to underlie both knowing-that and knowing-how. Besides, I have related above the notion 
of intuitive meaning to that of what-it-is-likeness. Here, Earl Conee argues that knowing what an experience is like consists in acquaintance with the experience, and such knowledge by acquaintance, which requires only a maximally direct epistemic relation to the experience, "constitutes a third category of knowledge, irreducible to factual knowledge or knowing how." ${ }^{39}$ Further, Eva-Maria Jung and Albert Newen very recently claimed that the Rylean dichotomy between knowledge-that and knowledge-how has to be replaced by a theory that distinguishes three different formats of knowledge: (1) propositional, (2) practical, and (3) image-like. Propositional and practical knowledge, respectively, roughly correspond to our knowing-that and knowing-how, whereas image-like knowledge is similar to knowing-what in that is somewhat unstructured such that its content is only partially explicable by concepts and their combinations. ${ }^{40}$

In this essay, the type of knowing-what with which we are concerned is a correct intuitive awareness about some object that bears the features delineated in the previous section. Lacking a propositional content, an intuitive awareness cannot be assessed for truth, but only correctness and its intentional content cannot be described adequately. Meanwhile, a knowledge-what would be a dispositional trace that results from a knowing-what awareness. Now, a correct intuition as a knowing-what is similar to a knowing-that in that it is broadly epistemic as it is intentionally directed to some external object and may reveal to the knower certain aspects of reality. In addition, it readily becomes a knowing-that or a conceptual judgment. However, it differs from a knowing-that in that it involves no explicit presence of concepts and is not structured by their composition. As a result, neither it nor its intentional content can properly be described; again, what is thus known cannot be transmitted and has to be acquired by everyone via their own experiences.

Like a knowing-how, a correct intuition has an ineffable dimension: its content cannot be matched by any list of propositions. It depends for its arising on repeated practice or nature/instinct. Yet, unlike a knowing-how, it concerns mainly the mind and senses, not the body. It is an intuitive understanding that comprehends its object meaningfully, rather than a successful manifestation of a skillful ability in bodily actions. Consequently, one knows what swimming is even if one does not know how to swim, yet it takes nothing short of a jewelry connoisseur's intuition to know what it is to discern a genuine jewel.

Not being endowed with language and conceptual thought, animals are unable to grasp propositions. They do not have factual or propositional knowledge. Nevertheless, rats in an eight-arm maze know, on the sight of a red sign, which arm of the maze to enter for food, and scrub jays know where to recover particular food items they previously cached. It is problematic to place such types of knowing under the same umbrella as one's knowing how to swim and chicks' knowing how to fly. In fact, we should cast doubts on the joint exhaustiveness of knowing-that and knowinghow, and I have sketchily shown that correct intuitive understanding qua knowingwhat needs to be distinguished from these two types of knowing. It is also palpable that the notion of knowing-what can help to bridge between them. ${ }^{41}$ 


\section{Concluding Remarks}

I have attempted to explicate Bhartṛhari's conception of pratibhā in its relation to the notions of meaning, understanding, and knowing. A pratibhā, we have seen, is a spontaneously arising, broadly word-tinged intuitive understanding about something. It is a knowing-what as well if it correctly apprehends an unstructured meaning of the thing. Further, it is not reducible to its verbal and nonverbal causal factors and cannot be described adequately. I have tried to provide a coherent rational reconstruction of the conception, although my reconstruction, being largely constrained by Bhartrhari's laconic exposition, remains incomplete.

Western philosophers used to think that the human being is the only creature endowed with a mind that thinks in terms of conceptual ideas, and is the only creature that possesses an articulate language. It is the use of language, as well as the exercise of rational thinking, that accounts for the intellectual superiority of humans over animals. Polanyi, however, cautions against such a view. The human gift of speech, he says, cannot itself be due to the use of language but must be due to some pre-linguistic capacities. Accordingly, we shall have to account for the acquisition of language in humans by acknowledging in them the same kind of inarticulate powers as we observe in animals. ${ }^{42}$ In the meantime, a number of recent studies in moral psychology suggest that people's moral judgments are generally the result not of a process of ratiocination and reflection but of moral intuitions. In a review of these studies, Jonathan Haidt writes:

Rather than following the ancient Greeks in worshiping reason, we should instead look for the roots of human intelligence, rationality, and virtue in what the mind does best: perception, intuition, and other mental operations that are quick, effortless, and generally quite accurate. ${ }^{43}$

While analysis and ratiocination need to be valued in our search for truth and knowledge, they may have to be supplemented by spontaneous holistic intuitions. Here, Bhartrhari's conception offers us an Indian Grammarian perspective on intuition that should be worthy of our consideration.

In contemporary scholarship, intuition is often said to occur quickly and effortlessly such that only the outcome, but not the process, is accessible to consciousness. The process is regarded as non-conscious, whereas the outcome is an intuitive judgment. We saw that one characteristic feature of the Bhartrharian intuition is that its intentional content is indescribable: one has an intuitive sense of what is an appropriate response to make here and now, but one cannot properly verbalize the sense-not to say the reasons for it. The term "intuitive judgment" would then be a misnomer for pratibhā. Such a position is indeed unconventional. Nevertheless, it accounts for the threshold state between the process and the judgment and better captures the immediate, not yet propositionally structured character of the suddenly arising intuitive experience. (After all, it takes some time for the mind to form a judgment!) The intuition, further, is related to the notions of knowing-what and 
of knowing what an experience is like. The notion of knowing-what gives us a third type of knowing aside from knowing-that and knowing-how. In addition, we know what it is like to see or hear, yet the nature of the knowing remains obscure. ${ }^{44}$ Overall, while more work needs to be done, I hope to have shown the relevance of Bhartṛhari's conception of pratibhā for contemporary philosophical studies of related topics.

Notes

An earlier draft of this article was read as a paper in two different seminars in Taiwan in 2010 and 2011. I am grateful to the participants, particularly Professor Norman Y. Teng and Dr. Cheng-hung Tsai, for their critical discussion and helpful suggestions. My thanks also go to the reviewers of Philosophy East and West for their valuable comments.

1 - For a critical edition of the Sanskrit text of the Vākyapadīya, see Rau 1977. Verse numbers in the present article are given according to that edition.

2 - Bhartrhari's presentation of the topic is laconic and requires hermeneutic elucidation, for which one may refer to Subramania lyer 1982, Tola and Dragonetti 1990, and Akamatsu 1994. However, the approach of these works is more philological than philosophical. Readers may also consult Coward and Raja 1990 for discussions of the relevant issues in the Grammarian school.

3 - For relatively recent discussions on the related issues, see Aklujkar 2001 and Bronkhorst 2001.

4 - Ogawa 1999, pp. 276-278; apart from the verses cited therein, one may refer to VP 1.51 and 88 (verses 51 and 88 of the first division or Kānda of the VP).

5 - VP 1.51 and the Commentary (the Vrtti) on it in Subramania lyer 1966, p. 109. (I assume that Bhartrihari is the author of the Vrtti.) What I take to be the act here is called the own form (ātmarūpa) in the verse. Both the act and the intentional percept (jñeyarūpa) are immanent in the awareness or consciousness (jñāna).

6 - The signifying word as the own form (svarūpa) of a word is called sphota in the $V P$, but I shall bypass this notion.

7 - VP 2.132. This verse states that the intentional object is understood to be the meaning of a word when it is known as an external object. In light of VP 2.445 and 3.7.6, I take this to mean that the intentional object is superimposed (bāhyīkṛtya, samāropya) on the external world. Cf. Ogawa 1999, pp. 271-276. The superimposition serves for Bhartrhari the important function of relating the inner image to the external world. Incidentally, although Bhartrhari gives other different views of word meaning, he seems, at least at the conventional level, to generally accept the present view. 
8 - VP2.445 speaks of sentence meaning as of the nature of awareness (sampratyaya), while VP 2.145 takes it to appear in the form of an object (vișaya). Thus, the meaning is an object immanent in the awareness of sentential understanding and is in this sense said to be intentionally immanent. The meanings of words constituting a sentence are also intentionally immanent, but they are said to be abstracted or analyzed out of the sentence meaning, while being externally imposed. Cf. VP 2.445-446.

9 - To save space, only my translations, not the Sanskrit originals of the verses quoted from the $V P$, are given.

10 - David Pitt (2004) has argued, I think quite convincingly, that conscious thoughts have proprietary phenomenal properties that outstrip any accompanying auditory or visual imagery - that what it is like to think a conscious thought (or understand a sentence) is distinct from what it is like to think any other conscious thought (or understand any other sentence) and from what it is like to be in any other kind of conscious mental state. Thus, there is something it is uniquely like to apprehend the meaning of a sentence.

11 - See Pitt 2004, p. 31.

12 - It seems for Bhartrhari that a thing is directly and properly expressible if it is independent in the sense of being determinately cognizable and is qualified by a distinct qualifier that functions as the basis for the application of the word concerned. Such a thing is structured or at least endowed with a qualifierqualificand division. A structureless thing, by contrast, can only be indirectly expressed by conceptually imposing such a division on it.

13 - VP 2.425, 439, 441. The ineffability of relation is explained mainly in the third chapter of the third division of the VP: 3.3.3-5, 19; see Houben 1995, pp. 170-213. Cf. Russell 1927, pp. 275-276, where Russell recognizes the unsubstantiality of relations and the difficulty of expressing them by words. After highlighting the ineffability of relation, Bhartrhari goes on in VP 3.3.20-24 to show why one can, without contradiction, speak of something by saying that it is ineffable; for an elaboration of this issue, refer to Ho 2006.

14 - Cf. VP 2.440, 3.3.54, 3.11.7, 3.14.475. For Bhartrhari, an indescribable thing mostly bears various properties and capacities, yet they are so intimately interwoven that the thing as such is indivisible. To express it, one needs to abstract from it a distinct form or impose on it an extraneous adjunct that serves to qualify it and functions as the basis concerned. This artificially divided or extraneously qualified thing is describable, but it is not the original thing. For exposition of such ideas, see the Commentary on VP 2.440 in Subramania Iyer 1983, p. 313, and Helārāja's commentary (the Prakīrnaaprakāśa) on VP 3.11.7 in Subramania lyer 1973, p. 98.

15 - The Commentary on VP1.132 asserts that when an object freshly presents itself to consciousness without any basis for the application of words being cognized 
therein, it appears in an unspecifiable (avyapadeśya) way as "it is this." There may seem to be a tension between this assertion and VP 2.144. However, the use of the word avyapadeśya (literally meaning "indefinable" or "unspeakable $e^{\prime \prime}$ ) here suggests otherwise, and we may take the object-and the intuitive meaning-to be only indirectly expressible by an expression such as "it is this" or by a demonstrative like "this."

$16-V P 2.145,419,444$.

17 - VP 2.234, 425, 442, 446; 3.3.81.

18 - Polanyi and Prosch 1975, p. 33.

19 - Polanyi 1958, p. 57.

20 - Polanyi 1958, pp. 62-63, 87-93; Polanyi 1959, pp. 44-46; Polanyi 1969, pp. 123-127, 132.

21 - Cf. Polanyi 1958, pp. 87-93. Polanyi states on p. 90: "by acquiring a skill, whether muscular or intellectual, we achieve an understanding which we cannot put into words and which is continuous with the inarticulate faculties of animals." On pp. 91-92, he takes one's focal knowledge of the meaning of a text to be inarticulate knowledge.

22 - Cf. VP 2.7, 25, and Tola and Dragonetti 1990, p. 96.

23 - Modern scholars in the fields of psychology, philosophy, and management have offered various definitions and characterizations of intuition; see the discussions in Shirley and Langan-Fox 1996 and Dane and Pratt 2009. Of course, I am concerned mainly with the characterizations given in the present article to the notion of pratibhā.

24 - By "intentional content" I mean the ideal content that is immanent in consciousness as the intentional correlate of the act of awareness concerned, which would, in the case of intuitive understanding, be said to be an intuitive meaning (in a rather stretched sense of the term "meaning").

25 - VP 1.129-131 and its Commentary.

26 - See the Commentary on VP 1.129, 131-132. Roughly, articulate words are inner, unspoken words that can properly be articulated as audible words, while inarticulate words cannot. For Bhartrhari, thinking amounts to an inner silent speech that consists of a series of such articulate words and their correlated meanings.

27 - Apart from words and linguistic traces, Bhartrhari, in VP2.152, lists nature and training/practice among six kinds of causal factors that help to bring about an intuitive understanding (the other four kinds are somewhat exotic). He does note that some animals can be trained such that hearing of specific sounds induces in them an intuitive understanding about what to do in response to the sounds; see VP 2.117-118 and the Commentary on VP 1.123. 
28 - In the Commentary on VP 2.152, an expert digger's intuition of where to dig a well is considered an intuitive understanding that results from practice. In situations related to expertise, an expert knows, almost spontaneously, what to do, yet may not be able to explain the reasons for his or her judgment.

29 - Polanyi and Prosch 1975, p. 40; Subramania Iyer 1966, p. 93.

30 - People may speak of expert wine tasters and chicken sexers as possessing specific skills. One may be said to possess the skills of understanding a certain language. Such skills are intellective in the sense of being correlated with discernment and understanding. However, here, I use the notion of skill only to refer to embodied, action-centered, and non-intellective skills that are developed through actual bodily performance, but not to intellective skills, although the borderline between the two types of skills can be somehow fussy.

31 - Watson 1968, p. 153.

32 - If the notion of inarticulate words seems unappealing, we may consider Michael Dummett's (1994, p. 125) notion of proto-concept. While a cat cannot have any concepts, properly so called, it may possess proto-concepts, which we share with animals without language. Proto-concepts constitute proto-thoughts, and I shall soon discuss Dummett's notion of proto-thought.

33 - Subramania Iyer 1966, p. 75. Subramania lyer (1982, pp. 54-55) and Tola and Dragonetti (1990, p. 110) take pratibhā to occur in ordinary sense perception, although they do not give textual evidence.

34 - Dummett 1994, pp. 121-126. Dummett contends that to attain an adequate account of perception, we adult human beings must be regarded as frequently engaging in proto-thoughts, voluntarily and involuntarily.

35 - Dane and Pratt 2009, pp. 12-16. Surely, the Bhartṛharian intuition is only akin to, but not identical with, the intuitions discussed in modern scholarship.

36 - See Stanley and Williamson 2001, Snowdon 2003, and Bengson and Moffett 2007.

37 - For example, Noë 2005, Wallis 2008, and Jung and Newen 2010.

38 - No commitment need be made here to a particular kind of warrant; any will do for the present purposes.

39 - Conee 1994, p. 136.

40 - Jung and Newen 2010, pp. 124-130. However, their approach centers only on knowledge we have of our actions and is therefore not very pertinent here.

41 - If, as Subramania lyer holds (1982, p. 54), pratibhā takes place all the time in us, it would often remain only implicit and subconscious, and yet probably be integral to knowing-that and knowing-how. I shall not pursue this issue here. 
42 - Polanyi 1958, p. 70.

43 - Haidt 2001, p. 822. Intuition is here said to be common to all mammals; it is reported that people typically cannot tell how they really reached a moral judgment. Significantly, Puṇyarāja, an ancient commentator on the VP, commenting on VP 2.147, takes the manifestation of people's good conscience to be an instance of pratibhā; see Subramania lyer 1983, p. 66.

44 - For the difficulties of classifying the knowing as knowing-that, see Mellor 1993, pp. 7-9. For some of the difficulties involved in classifying it as knowing-how, see Snowdon 2003, pp. 22-25.

\section{References}

Akamatsu, Akihiko. 1994. "Pratibhā and the Meaning of the Sentence in Bhartṛhari's Vākyapadīya." In Bhartṛhari: Philosopher and Grammarian, edited by Saroja Bhate and Johannes Bronkhorst, pp. 37-43. Delhi: Motilal Banarsidass.

Aklujkar, Ashok. 2001. "The Word Is the World: Nondualism in Indian Philosophy of Language." Philosophy East and West 51, no. 4:452-473.

Bengson, John, and Marc Moffett. 2007. "Know-how and Concept Possession." Philosophical Studies 136, no. 1:31-57.

Bronkhorst, Johannes. 2001. "The Peacock's Egg: Bharṭ̣hari on Language and Reality." Philosophy East and West 51, no. 4:474-491.

Conee, Earl. 1994. "Phenomenal Knowledge." Australasian Journal of Philosophy 72 , no. $2: 136-150$.

Coward, Harold G., and K. Kunjunni Raja, eds. 1990. Encyclopedia of Indian Philosophies. Vol. 5, The Philosophy of the Grammarians. Princeton, NJ: Princeton University Press.

Dane, Erik, and Michael G. Pratt. 2009. "Conceptualizing and Measuring Intuition: A Review of Recent Trends." In International Review of Industrial and Organizational Psychology, edited by G. P. Hodgkinson and J. K. Ford, pp. 1-40. Chichester: John Wiley and Sons.

Dummett, Michael. 1994. Origins of Analytical Philosophy. Cambridge, MA: Harvard University Press.

Haidt, Jonathan. 2001. "The Emotional Dog and Its Rational Tail: A Social Intuitionist Approach to Moral Judgment." Psychological Review 108, no. 4:814-834.

Ho, Chien-hsing. 2006. "Saying the Unsayable." Philosophy East and West 56, no. $3: 409-427$.

Houben, Jan E. M. 1995. The Sambandha-samuddeśa and Bhartrhari's Philosophy of Language. Groningen, The Netherlands: Egbert Forsten. 
Jung, Eva-Maria, and Albert Newen. 2010. "Knowledge and Abilities: The Need for a New Understanding of Knowing-how." Phenomenology and the Cognitive Sciences 9 , no. $1: 113-131$.

Mellor, D. H. 1993. "Nothing Like Experience." Proceedings of the Aristotelian Society $93: 1-15$.

Noë, Alva. 2005. "Against Intellectualism." Analysis 65, no. 4:278-290.

Ogawa, Hideyo. 1999. "Bhartṛhari on Representations (Buddhyākāra)." In Dharmakirti's Thought and Its Impact on Indian and Tibetan Philosophy, edited by Shoryu Katsura, pp. 267-286. Vienna: Verlag der Österreichischen Akademie der Wissenschaften.

Pitt, David. 2004. "The Phenomenology of Cognition or What Is It Like to Think That P?" Philosophy and Phenomenological Research 69, no. 1:1-36.

Polanyi, Michael. 1958. Personal Knowledge: Towards a Post-Critical Philosophy. London: Routledge and Kegan Paul.

— 1959. The Study of Man. Chicago: University of Chicago Press.

- 1969. Knowing and Being. Edited by Marjorie Grene. Chicago: University of Chicago Press.

Polanyi, Michael, and Harry Prosch. 1975. Meaning. Chicago: University of Chicago Press.

Rau, Wilhelm, ed. 1977. Bharṭ̣haris Vākyapadīya: Die Mūlakārikās nach den Handschriften herausgegeben und mit einem Pāda-Index versehen. Wiesbaden: Kommissionsverlag Franz Steiner GMBH.

Russell, Bertrand. 1927. An Outline of Philosophy. London: George Allen and Unwin.

Ryle, Gilbert. 1949. The Concept of Mind. London: Hutchinson.

Shirley, Debbie A., and Janice Langan-Fox. 1996. "Intuition: A Review of the Literature." Psychological Reports 79, no. 2:563-584.

Snowdon, Paul. 2003. "Knowing How and Knowing That: A Distinction Reconsidered." Proceedings of the Aristotelian Society 104, no. 1:1-29.

Stanley, Jason, and Timothy Williamson. 2001. "Knowing How." Journal of Philosophy 98, no. $8: 411-444$.

Subramania Iyer, K. A., ed. 1966. Vākyapadīya of Bhartṛhari with the Commentaries Vṛtti and Paddhati of Vṛsabhadeva. Kāṇḍ I. Pune, India: Deccan College.

— ed. 1973. Vākyapadīya of Bharț̣hari with the Prakīnnaprakāśa of Helārāja. Kāṇda III, Part II. Pune, India: Deccan College.

— 1982. The Vākyapadīya: Some Problems. Pune, India: Bhandarkar Oriental Research Institute. 
— Ancient Vṛtti. Kāṇụa II. Delhi: Motilal Banarsidass.

Tola, Fernando, and Carmen Dragonetti. 1990. "Some Remarks on Bhartṛhari's Concept of Pratibhā." Journal of Indian Philosophy 18, no. 2:95-112.

Wallis, Charles. 2008. "Consciousness, Context, and Know-how." Syntheses 160, no. $1: 123-153$.

Watson, Burton, trans. 1968. The Complete Works of Chuang Tzu. New York: Columbia University Press. 